\title{
A Location-Based and Contextualized Mobile Services Approach To Providing Information and Services in the Tourism Industry
}

\author{
António CARVALHO, Elisabete Paulo MORAIS and Carlos R. CUNHA
}

Instituto Politécnico de Bragança, Campus de Santa Apolónia, 5300-253 Bragança, Portugal

Correspondence should be addressed to: António CARVALHO; antcarvalho@ipb.pt

Received date: 14 November 2018; Accepted date: 26 April 2019; Published date: 25 June 2019

Academic Editor: Roberto Paiano

Copyright (C) 2019. António CARVALHO, Elisabete Paulo MORAIS and Carlos R. CUNHA. Distributed under Creative Commons CC-BY 4.0

\begin{abstract}
Todays' market is ruled by several mobile devices applications for all types of proposes. Still, for many destinations, it lacks applications that work in an integrated way, combining cooperative mechanisms that allow the effective support the wide range of tourists need when they visit a destination. Many applications, currently available, to the tourism industry are limited in content and cultural offerings, and commercial applications only communicate with their partners and have no cultural content. This paper presents a framework of a mobile application implementation to support the tourist information needs when tourists are visiting the Portuguese city of Mirandela in which interest points are combined with commercial content. The presented model allows the tourist to have only one application that integrates the contents that he wishes/subscribes, both cultural and commercial, creating a parametrizable universal profile that can be accessed by any of the entities in the system. This approach will benefit both tourists and entities involved. This will also allow increasing the dissemination of regional products and/or services and thereby increase their market potential and consequently their sales.
\end{abstract}

Keywords: tourism, framework, ubiquitous computing, contextualization.

Cite this Article as: António CARVALHO, Elisabete Paulo MORAIS and Carlos R. CUNHA (2019)," A Location-Based and Contextualized Mobile Services Approach To Providing Information and Services in the Tourism Industry", IBIMA Business Review, Vol. 2019 (2019), Article ID 699245,

DOI: $10.5171 / 2019.699245$ 


\section{Introduction}

Although there were already tourists in ancient Greece, only in the nineteenth century did someone appear to promote tourism. Thomas Cook (Towner, 1995), then, created the first organized tour of history. It would follow the creation of a travel agency and the promotion of tourism would be its activity. At a later stage, the concept of hospitality has appeared as we know, thanks to Cesar Ritz (Jones, 1999), who modernized the sector a lot. But the first and second world wars came to shake the tourism sector and only in the second half of the twentieth century, has tourism approached the current concept, mainly driven by international stability and a certain development of leisure culture, mainly in Western Europe (Apostolopoulos, et al., 1996).

Nowadays, with the evolution of the information society, more and more people want not only to obtain detailed information about the destinations to visit, but also to have support mechanisms for the actual travel phase and even the "after travel". The current tourist is no longer satisfied to see a brochure and wants more. They want to be able to search everything about this region before opting to visit it and can publish their experience with other users, with the certainty that the information made available after the visit will be useful to anyone planning to move to their point of interest. The generation that is currently between 20 and 35 years old, called Generation Y or Millennials, places a lot of emphasis on the comments shared on the Internet before making any decision, and feels responsible for sharing information in order to continuously feed the "network" (Cadavez, 2017).

These are data that justify the bet on the introduction of new technological information systems to support tourists and tourism (Brown \& Chalmers, 2003). Traditionally, the industry is focused on the application of technologies to support Business-to-Business (B2B) models, in which the consumer has no possibility of interacting. This model works well for the pre-trip phase, but it is at the stage where the tourist is at the site to visit that they notice the major flaws in the availability of the information. Although there is the concept of ubiquitous computing in which a computer is not needed to access information (Weiser, 1991) and even the evolution of devices may lead one to believe that they are "invisible" and are everywhere (Watson et al. al., 2002), it can be seen that the evolution in the tourist support applications for mobile devices could be more developed. And it is at this stage that tourists need more information (Watson, et al., 2002). It is when they are visiting the place that it becomes useful to have a tool that allows providing the necessary information to tourists when they need it.

One of the methods used to obtain information is the Internet. In the digital age, the web and social media growth dramatically changed the way we travel, providing a platform where everything can be broadcasted (Li, et al., 2018). Currently, any tourist region has detailed information on websites and blogs or forums to be consulted before the tourist makes the decision on which destination to choose for their vacation and even locally, where they have tourist offices which the tourist can visit to get more detailed information about the region.

Most of the relevant applications currently found are for the preparation phase of the trip. Among these applications or websites, we can highlight online travel agencies such as expedia.com (Holmberg, 2009) because they allow you to purchase complete packages with flight, hotel and car or other extra activities. There are also some websites that combine the three phases of the trip. An example is tripadvisor.com.

For the "after visit", there are some websites sharing information. It is emphasized that it is possible to add photos and comments on the website itself as it happens in social networks. An example is travelblog.com where any user can enter photos of their travels. 
As for the applications for mobile access, the most that stand out is for the stage during the trip. Examples are the applications CloudGuide ${ }^{1}$, Viseu Mobile (Martins, et al., 2015), Urbis (Farias, et.al., 2017) or the Mobile Guide - TAIS (Kashevnik, et.al., 2017).

With commercial scope, in addition to the already mentioned expedia and tripadvisor, there are applications created by companies or business groups which target more the area of customer loyalty in which, in certain cases like Lyoness or FreeBee, a network of companies is created that together add value to the services provided to customers, but it fails to present tourism and cultural content in such applications.

It is noted that when tourism or culture is the focus, commercial issues are not considered and, on the other hand, there is the commercial applications market that ignore the aspects valued by the tourist.

It is possible to create an application that meets these two paradigms. It supports the tourist when he is visiting the region giving him useful information about the points of interest that he can see and which routes he can follow to reach these points and it supports the local commerce divulging promotions and campaigns to the tourists, preferably based on their tastes, to which the tourist will be tempted to consume.

The framework to be created, since it is an integrator of tourist and commercial services, must have support technology in real time. It cannot be limited to a simple positioning mechanism such as GPS (Global Positioning System), as are some of the applications referred to because the context of the tourist user of the application may be different according to the time of day, the availability that has to explore the area and their interests and the tourist tends to be lazy, we have to adapt to the tourist and not the opposite to succeed (Wearing, et al., 2017). It is necessary to go further and be able to inform the tourist, on his profile, about what is interesting for him, when relevant.
The profile of the tourist must be customizable and easily accessible by the tourist himself. Being a common profile, the tourist can define what he wants to know, when and where and only to be notified under these conditions and since there is an intersection with commercial applications, the tourist's buying profile easily integrates and suggests what may be to "the liking of the" even if he did not choose this option in the profile.

\section{State of Art}

From the appearance of the mobile phone to the present, there was a rapid evolution that allowed the significant improvement of the devices in short periods of time. If mobile phones were only used to make and receive phone calls and short messages, in the 1990s, technologies (e.g. camera, wireless connectivity, GPS) were being incorporated, along with support of external programs (in JAVA) enabled the implementation of functionalities on the base system to optimize the experience of using the device. The great change of paradigm takes place from 2007; the time of the launch of the first smart phone. In the generation of the Smartphone, there are several mobile operating systems and the ones with the highest market share are Android and IOS and so the applications are for one of these systems, or in some cases for both with a version of the application for each operating system.

While this is a market with a lot of potential and there are already plenty of applications available, there is still a notable gap in some aspects, namely; in the integration of services, even if the offer at the application level is already considerable. Following are some projects that have successfully implemented applications to support the tourist adaptation to Smartphone.

\section{CloudGuide}

CloudGuide $^{1}$ is a mobile tour guide that is available in dozens of cities worldwide. Originating in Spain, the platform quickly spread to cities in other countries. The application is an interactive guide, with information of cultural spaces (essentially 
museums), available in the cities where the platform has already been implemented. Being a newer application, it has a design advantage, but only differs in the contextualization method and has the functionality of having complete guides that can be transferred in advance in case there is no network at the time of the visit. The application uses a relatively recent contextualization mechanism, Beacons; where when a tourist's presence is detected alongside a part of the museum, a notification with relevant, complementary information about that part is sent to the application, although it is not specified on the website what information is provided to the tourist and in what format.

\section{Viseu Mobile}

Viseu Mobile (Martins, et al., 2015) was a tourist guide created for the city of Viseu, Portugal, published it with the name "Viseu na palma da mão" in which a map of the city of Viseu added layers of contents resorting to reality augmented with the aim of enriching the tourist experience in the city.

After the installation of the application, the tourist could begin the visit to the city in which the layers captured by the camera applied the layers of contents, among them, images, descriptions or historical facts or could define points of interest, and the application generated a route optimized for the visit to these points of interest and showed it on the map. As the points of interest were grouped by topology, it was possible to search for several similar points of interest (e.g. churches) and how far they are from the point where the application was used.

However, the application has been discontinued, but there are still some dispersed resources available on the internet with a search in the search engines.

\section{Urbis}

The Urbis application (Farias, et.al., 2017) created for the Brazilian city of Recife, with a prototype developed for the Android platform (4.0 or higher), requires a data connection to communicate with the servers, either on maps or using a clientserver model for communication.

After authentication, the application shows a menu with the points of interest of the city and by clicking on one of them, the information about this point is presented. You can also add actions to the point of interest, such as calling there, seeing the route on the map from where the tourist is to the point of interest or knowing your story better. With GPS enabled, the application redirects the user to a map application such as Google Maps, so you can easily move to that point of interest.

It is also possible for the user to store the points of interest in a private list accessible in the application itself, so that they can visit them later.

\section{Mobile Guide - TAIS}

The Mobile Guide application - TAIS (Kashevnik, et.al., 2017) implemented for the Russian city of St. Petersburg is another context-sensitive tourist guide in which it presents to the tourist and application user the chosen points of interest based on their preferences and current situation.

For the integration of these factors, the application in addition to having a database with the information of points of interest, still uses external databases to obtain complementary information (e.g. photographs of the point of interest, weather conditions, public transport schedules, etc..), that after crossing with the user profile, it generates a recommendation of the points of interest to visit.

The application uses an algorithm that, based on the available information, orders the points of interest in a "ranking" where at the top will be the most appealing to the tourist in the current conditions. The same tourist in the same place on different days can get different rankings ordered based on the other factors analyzed by the system. 
The application also integrates with the "Ford SYNC" application where, in a vehicle with this equipment, the list of points of interest is transmitted to the vehicle navigation system.

\section{Critical analysis of applications}

Although there are currently many mobile applications, there is a noticeable shortage in tourist support applications for ubiquitous environments and those that are too specific and with few interactivity options (Fernández-Cavia, et al., 2013).

The mobile environment applications studied are too specific, that is, they are focused on a single aspect, forgetting the rest. For example, in an application where the location for obtaining content is done by GPS, there is no other method of relating the tourist to the location without being by the coordinates of that location. It is noted that there are missing applications that can interconnect with various contextualization mechanisms, based on the paradigm of ubiquity and smart spaces that soon are increasingly becoming a reality.

\section{Commercial Applications}

Since always the greatest promoter of tourism has been the service providers in this area. If tourism currently has the impact it has, much is due to the dissemination and services provided by a network of companies that promotes a certain region or point of interest with the aim of attracting people and thereby increasing turnover.

\section{Loyalty systems}

About 10 years ago, companies began to realize that it is easier to sell several products to the same person than to sell only one to several people. Until Sonae launched the "Cartão Continente" card in 2007, little thought was given to multicompany loyalty systems in Portugal. Although the card is restricted to the group of brands of the parent company; Sonae, it is a fact that the ability to have a discount card at a sports store using credit accumulated in grocery shopping is an innovative concept.

It was not only in Portugal that this trend became widespread. It was the year 2003, when in Graz in Austria appeared the card Lyoness that in a short time had a community of purchases in which several independent companies accepted the same card and gave discounts to the customers.

This type of card has at least two advantages over the generic card that many brands have: it has cross-selling between brands, that is, a brand A customer goes to brand $\mathrm{B}$ for accepting the card and has a low cost, because a million euro structure like the "Cartão Continente" is paid by thousands of small businesses and can access a platform at the same level for a few hundred euros.

In Portugal, we also have FreeBee which is another loyalty system in which the user has a card, virtual in the case, and can access discounts and specific promotions for cardholders.

In this card, home business is free to set the discounts and it is only enough for the card to be registered for the discount to be made. As there is no physical card, validation is done by the telephone contact provided in the registry or by QRcode that can be obtained in the mobile application or printed from the area reserved on the site.

\section{Integration of systems}

It was currently unthinkable that a card, like the one mentioned in the previous point, did not have a whole series of platforms and support applications. Although in the early days of loyalty cards, it was only possible to obtain information on points, discounts and campaigns in the participating stores, this concept is currently outdated. Even with the information presented on each purchase invoice, all cards have websites and mobile applications where the user can have access to everything that is relevant to the system concerned. 
However, there is some resistance in the adoption of more advanced technologies such as NFC (Near Field Communication) or RFID (Radio-Frequency Identification). Ten years ago, Simões (2008) presented, in his study, a customer card implementation solution using NFC technology already available on some Smartphones and currently common. According to the author, it was not comfortable to carry dozens of cards in the wallet when you could have a digital wallet on the phone with all the cards available. At that date, the author did not predict the possibility of the same card being used in several companies as it is verified that it already exists today.

Currently, almost all Smartphones support this technology and although it has a lot of potentials, still few solutions are implemented based on NFC.

\section{Commercial applications in tourism}

The applications presented are the example of what you can do today to ensure the increase of customers and, consequently, the increase of sales of a certain company.

It was easy to include sights in the network of stores presented and have only one application that simultaneously enables visiting a region and getting discounts in the stores of the region but currently does not. The information points of tourism regions only provide information on cultural heritage and activities, but do not see commercial information in these contents, nor the reverse; cultural content between the promotions of companies adhering to any of the platforms presented.

In addition, the concept of U-commerce is not new, but according to Kumar, et.al., (2015), there are still four barriers to transpose, which he calls 4 S's: systems, standards, security and simplicity. Today's systems are still based on complex standards where it is difficult to achieve integration of emerging technologies at a low cost, and the motivation for exploring new methods of communication with the customer comes up against these points.
Although with common interests, the companies of a certain region, as well as the entities responsible for a certain tourist region that also promote the divulgation of the same and, in certain cases, events of diffusion of the local market, have their methods of disclosure, but in terms of global applications, we do not see the necessary integration so that the tourist has a common interface in the exploration of the tourist region; an integration that would easily be implemented as we will see in the next chapter.

\section{Proposed Framework}

Knowing that the tourist is by nature a good consumer, if we give him an application that can be used in a certain area, where he is offered the services of several companies, he will accept them, allowing these companies to share information between them increasingly and can also combine synergies to meet tourist's needs (Mendonça, et al., 2015).

The problem is that, currently, it is not yet thought of integrated. There are applications of geographical scope for the dissemination of contents and points of interest to the tourist and applications of commercial scope, only with the purpose of promoting the sale of products or services of the adherent companies that do not have cultural contents or vocation for the tourism sector.

\section{Integration of technologies}

As mentioned in the second chapter, the existing applications for the tourism sector are mainly focused on a single technology. The idea of the application may even be good, but it must be appealing to the tourist to use, or even if the tourist installs it, the return obtained may be very low or zero (Fang, et al., 2017).

In the case of tourism, there are concrete situations in which different technologies must be used in order to satisfy the tourist's needs. As an example, we can have the GPS technology that is very good in 
localization and useful for the elaboration of routes for the tourist, but it has an error in the approach of distances of less than one meter.

To overcome this failure and the fact that there is no GPS signal indoors, there are other technologies such as QRcodes, NFC tags or Beacons that allow closer interaction with the tourist, not only have a lower coverage, but also allow propagating the information only to those who request it. If a tourist does not activate the communication, there will be no communication.

This framework still must allow a part of insertion and an update of the information. Given the nature of the information to insert, this part should be developed for PC, and whoever is managing the system does not necessarily have to use a mobile device, as it has the PC that has many more features and functionalities. Thus, in addition to the integrated system for mobile technologies, there will also be a management and administration part of the system that will be connected by another method (via internet) to the application server to insert and/or update the contents available to the tourist.

Figure 1 describes the framework, then there is a part of providing information to the tourist to the mobile system, to implement the necessary services and interconnect the necessary technologies to the context where the tourist is located, and a part accessible from PC where the person who manages the system can change the available information, and these changes will propagate, in real time, to the tourist.
This framework is oriented to the mobile devices, integrating multiple mechanisms of contextualization in order to always serve the tourist in whatever circumstance he may be in. In order to serve the tourist, external services are also added by the platform in a common interface and the tourist is also provided with a PC access in which it is possible to have a range of options available and often these options do not necessarily have to be consulted during the trip. As an example, refer to the hotel reservation before traveling to the place to visit. Any of these external services, whether for the period of travel or outside it, is obtained through a network of partners providing such services, who will make the services they provide available in the system, as well as the conditions under which they provide them.

The tourist will have in his mobile device an application that will communicate with the application server to obtain the information when it is necessary, any of the mechanisms of positioning or contextualization will have the capacity to interact with the application and obtain relevant information for the tourist. The server will be running a server application for the mobile application; a Web server that will host a website where there will be system management, and a database server that will have a common database for all system interfaces. This server application will be based on Web Services that will interact directly with all parties involved in the system. Both the tourist and the content providing partners will have mechanisms that allow them to interact with the application, thus always ensuring the integration of information between the parties and a quick updating of the contents available. 


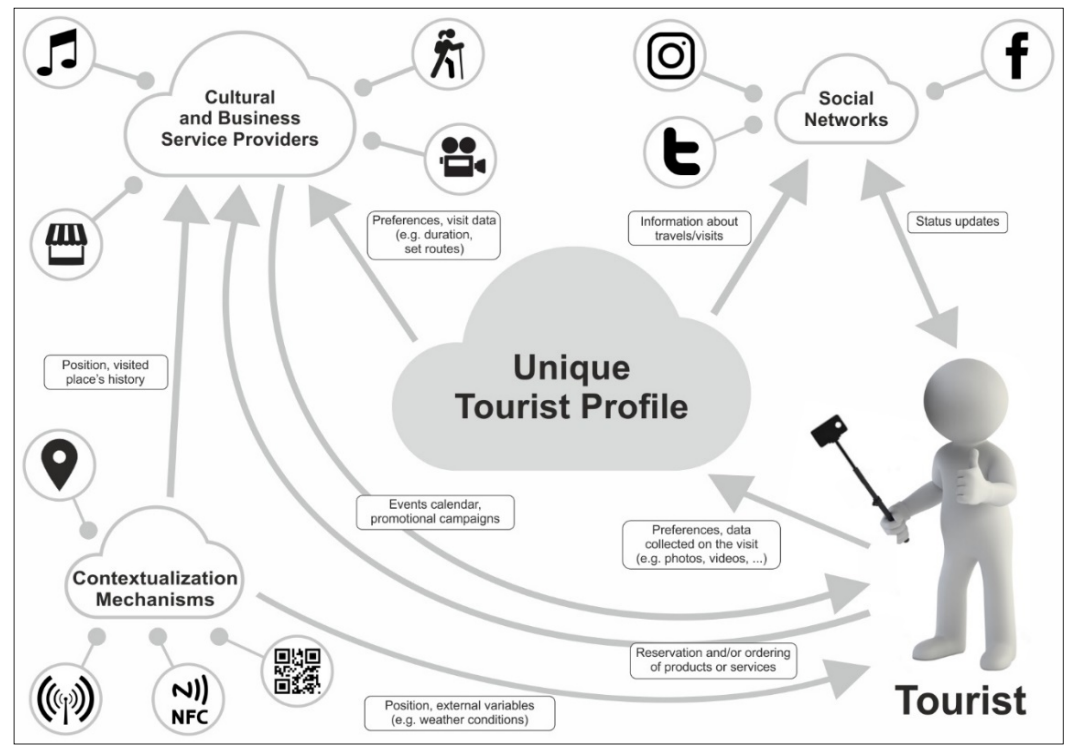

Fig. 1: Proposed Framework

\section{Unique profile for the tourist}

As a unique platform to add tourist and commercial support services, it is interesting that there is a unique profile where the tourist can register their preferences and thus not to be subject to receive information about products or services that are not of your interest.

In the applications presented in chapter 3, there are permission options for receiving advertising content to which the user gave permission to be sent, but usually what happens is there is no record of how and when the user gave permission or there is a standard checkbox where it is usually noted only when you object to data processing.

By creating a unique shareable profile among system actors, only a user's communication is enough so that the only stored record can be eliminated or corrected, thus avoiding multiple requests to various entities and, as is uniform, all stakeholders in the system have access to the same information thus ensuring to the tourist that information is not shared without their permission.

\section{And after the trip?}

So far, we have only thought about the trip itself, but there is a lot of information that can be collected during the trip for future reference. Whether with photography, video or other media, information about the trip is stored in order to remember what has happened and what happened.

This framework must have functionality that allows direct interaction with social networks, and/or a method that allows the storage of information for future publication. Even applications like booking.com have this kind of functionality. When searching for a hotel they show photographs sent by users, besides the part of the criticisms of the users that is of the most value. 
Even if the tourist is not adept at social networking, he can always upload photos or other contents and share them with the application community. So, anyone with the application installed can access information on the points of interest to visit from the perspective of the tourist who shared this information. This creates a greater interaction with the application and even increases its use because there will be people who have never even visited the region will install it just to access and see these contents.

\section{Conclusion}

This century saw an unprecedented increase in the number of mobile applications and mobile users. With this, there is a pervasive view in which applications will be permanently available and their contents will be accessible anytime, anywhere and will be based on the user's location and context (Bahl, et al., 2002; Cunha et al., 2010).

The proposed framework aims to be an enabler of innovative ways to provide information and services to tourists and to be a gateway to a business network and can also be used by the local community on the commercial side or by tourists in various locations if it is found available.

For future work, this framework will be the basis for an application of support to the tourist as a visitor to the Mirandela region, not forgetting, however, the part of the content availability for the "before the trip" and "after the trip" phase, satisfying with this the needs of the tourists from the decision process of the visit, through the accompaniment in the visit and culminating in the sharing of the experiences obtained.

1 https://www.cloudguide.me/, accessed May 29, 2018

\section{Acknowledgments}

UNIAG, R\&D unit funded by the FCT Portuguese Foundation for the Development of Science and Technology, Ministry of Science, Technology and Higher Education. UID/GES/4752/2019.

\section{References}

1. Apostolopoulos, Y., Leivadi, S. and Yiannakis, A. (1996) 'The sociology of tourism: theoretical and empirical investigations', Routledge.

2. Bahl, P., Balachandran, A., Miu, A. K. L., Russell, W., Voelker, G. M. and Wang, Y. (2002) 'PAWNs: Satisfying the Need for Ubiquitous Connectivity and Location Services', IEEE Personal Communications Magazine (PCS), 9 (1).

3. Brown, B. and Chalmers, M. (2003) 'Tourism and mobile technology', Proceedings of the eighth conference on European Conference on Computer Supported Cooperative Work.

4. Cadavez, C. (2017) "Mas que mundo é este?", ou de como tem de ser diferente a divulgação das práticas de fruição cultural para os turistas millennial - um estudo de caso pensando nos museus'. (Portuguese). Revista Iberoamericana De Turismo, 7(3), 215. doi:10.2436/20.8070.01.71

5. Cunha, C. R.; Peres, E.; Morais, R.; Bessa, M; Reis, M. C. (2010). "Contextualized Ubiquity: A new opportunity for rendering business information and services". In Journal of Theoretical and Applied Electronic Commerce Research, Universidad de Talca - Chile, vol. 5, issue 3, pp. 55-64. ISSN 0718-1876.

6. Fang, J., Zhao, Z., Wen, C., and Wang, R. (2017) 'Design and performance attributes driving mobile travel application engagement'. International Journal of Information Management, 37269-283. doi:10.1016/j.ijinfomgt.2017.03.003

7. Farias, I., Leitão, N. and Teixeira, M. M. (2017) 'Urbis: A touristic virtual guide', 12th Iberian Conference on Information Systems and Technologies (CISTI), Lisbon, 2017, pp. 1-6. doi: 10.23919/CISTI.2017.7975918

8. Fernández-Cavia, J. and López, M. (2013) 'Communication, destination brands and mobile 
applications'. Comunicación

Sociedad, 26(2), 95-113.

9. Holmberg, S. R. and Cummings, J. L. (2009) 'Building Successful Strategic Alliances: Strategic Process and Analytical Tool for Selecting Partner Industries and Firms', Long Range Planning, vol. 42, issue 2, 164-193.

10.Jones, P. (1999) 'Operational issues and trends in the hospitality industry', International Journal of Hospitality Management, 18 (4), 427-442.

11.Kashevnik, A. M., Ponomarev, A. V. and Smirnov, A. V. (2017) 'A multimodel context-aware tourism recommendation service: Approach and framework', Journal of Computer And Systems Sciences International, (2), 245. doi:10.1134/S1064230717020125

12.Kumar, S., Joshi, P., and Saquib, Z. (2015) 'Ubiquitous Commerce: The New World of Technologies', International Journal of Life Science and Engineering, 1(2), 50-55.

13.Li, J., Xu, L., Tang, L., Wang, S. and Li, L. (2018) 'Big data in tourism research: A 19.expanding the universe of marketing', Journal of the Academy of Marketing Science, 30 (4), 329-343.

20.Wearing, S. L., and Foley, C. (2017) 'Understanding the tourist experience of cities'. Annals of Tourism Research, 6597107. doi:10.1016/j.annals.2017.05.007

21.Weiser, M. (1991) 'The Computer for the 21st Century', Scientific American, 265, 11. literature review', Tourism Management, Volume 68, 2018, pp. 301-323. https://doi.org/10.1016/j.ipm.2017.10.00 6

14.Martins, M.L., Malta, C. and Costa, V. (2015) 'Viseu Mobile: Um guia turístico para dispositivos móveis com recurso à Realidade Aumentada', Dos Algarves: A Multidisciplinary e-Journal, 26(1), 8-26. DOI:10.18089/DAMeJ.2015.26.1.1

15.Mendonça, V., Varajão, J. and Oliveira, P. (2015) 'Cooperation networks in the tourism Sector: Multiplication of business opportunities', Procedia Computer Science, 64, pp. 1172-1181

16.Simões, D. (2008) 'Sistema de Fidelização sobre NFC (Near Field Communication)', Lisboa.

17.Towner, J. (1995) 'What is tourism's history?', Tourism Management, 16 (5), 339-343.

18.Watson, R.T., Pitt, L.F., Berthon, P. and Zinkhan, G.M. (2002) 'U-commerce: 